\title{
Increased airway osmolarity inhibits the action of nitric oxide in the rabbit
}

\author{
M. Högman, J. Hjoberg, G. Hedenstierna
}

Increased airway osmolarity inhibits the action of nitric oxide in the rabbit. M. Högman, J. Hjoberg, G. Hedenstierna. (CERS Journals Ltd 1998.

ABSTRACT: Inhalation of nitric oxide (NO) is known to dilate preconstricted airways. In asthmatics, there are large variations in the effect of NO on airway tone. One explanation of these variations may be different degrees of airway wall oedema.

The effect of NO inhalation on methacholine (meth)-induced airway constriction was investigated in a rabbit model. Oedema and a change in osmolarity of the airways was achieved by hypertonic saline nebulization and hyperventilation with dry gas.

There was an increase in resistance to meth at a concentration of $3 \mathrm{mg} \cdot \mathrm{mL}^{-1}$, of $86 \pm 14 \mathrm{cmH}_{2} \mathrm{O} \cdot \mathrm{L}^{-1} \cdot \mathrm{s}$ (mean $\pm \mathrm{SEM}$ ) after oedema formation, compared with $46 \pm 16$ $\mathrm{cmH}_{2} \mathrm{O} \cdot \mathrm{L}^{-1} \cdot \mathrm{s}$ without oedema. Inhalation of 80 parts per million (ppm) NO failed to counter the increase in resistance due to meth, $92 \pm 14 \mathrm{cmH}_{2} \mathrm{O} \cdot \mathrm{L}^{-1 \cdot} \cdot \mathrm{s}$ after hypertonic saline nebulization. After hyperventilation of dry gas, the increase in resistance due to meth at $1 \mathrm{mg} \cdot \mathrm{mL}^{-1}$ was $27 \pm 11 \mathrm{cmH}_{2} \mathrm{O} \cdot \mathrm{L}^{-1} \cdot \mathrm{s}$ with $80 \mathrm{ppm} \mathrm{NO}$ and $28 \pm 5 \mathrm{cmH}_{2} \mathrm{O} \cdot \mathrm{L}^{-1} \cdot \mathrm{s}$ without NO.

In conclusion, the relaxant effect of nitric oxide-inhalation on the airway smooth muscle can be blocked by an increase in the osmolarity of the airway surface liquid. The mechanism of this inhibition of nitric oxide remains to be established. Eur Respir J 1998; 12: 1313-1317.
Dept of Clinical Physiology, University Hospital and Asthma Research Centre, University of Uppsala, Uppsala, Sweden.

Correspondence: M. Högman, Dept of Clinical Physiology, University Hospital, S-751 85 Uppsala, Sweden, Fax: 4618 664135

Keywords: Hypertonic saline hyperventilation

methacholine chloride

nitric oxide

rabbits

respiratory mechanics

Received: December 41997

Accepted after revision August 11998

This study was supported by the Swedish Medical Research Council No. 5315, the Swedish Heart-Lung Foundation, AGA AB Medical Research Fund, Sweden and Marquette Electronics, Milwaukee, WI, USA.
Endogenous nitric oxide modulates neural bronchoconstriction in both experimental animals [1] and humans [2]. NO is the only known neural bronchodilator of the inhibitory nonadrenergic noncholinergic nerves in human airways [3]. Inhalation of NO has been shown to reduce the response to bronchoconstricting agents in both animals [4-7] and humans [8, 9]. In a study on asthmatic patients, inhalation of $\mathrm{NO}$ at a concentration of 80 parts per million (ppm) reduced the airway resistance [8]; however, there were large variations. In some patients, no improvement at all was observed in airway tone after inhalation of NO, while others showed the same dilatory effect as for a $\beta_{2}$ agonist.

Asthma is an inflammatory disease, characterized by the migration of inflammatory cells into the airway wall and the formation of oedema. The increase in the osmolarity of the airway surface liquid seen during hyperventilation has been proposed as the stimulus for exercise-induced bronchoconstriction [10]. In a rabbit model, hyperventilation with dry gas causes an increased response to histamine with respect to resistance [11]. During nebulization with hypertonic saline there is a shift in the ion content of the airway wall. This shift of ions causes fluid accumulation, and hence, a transient oedema is formed [12]. It was hypothesized that the blunted response to NO inhalation in some patients with asthma is caused by an oedema or increased osmolarity of the airway wall. Therefore, the effectiveness of inhaled NO in a rabbit model in countering bronchoconstriction was investigated after nebuliza- tion of hypertonic saline; and after hyperventilation with dry gas.

In rabbits, as in humans, a concentration of Š 80 ppm $\mathrm{NO}$ is needed to exert a relaxing effect on bronchial smooth muscle $[5,6]$. In this study, concentrations of 80-300 ppm NO were used. Methacholine (meth) was used to induce bronchoconstriction and evaluate the bronchoprotective effect of the inhaled NO.

\section{Materials and methods}

New Zealand White rabbits of both sexes with a body weight of 3.0-3.7 kg were used. They were vaccinated against pasteurella and bordetella and maintained on water and $75 \mathrm{~g}$ high-protein pellets.day ${ }^{-1}$ ad libitum. The protocol was approved by the regional ethics committee on animal experiments.

\section{Anaesthesia and animal preparation}

Premedication was given i.m. with fluanisone and phentanylcitrate (Hypnorm; Janssen Pharmaceutica, Beerse, Belgium) at $0.2 \mathrm{~mL} \cdot \mathrm{kg}^{-1}$. Neuroleptic anaesthesia $(0.3 \mathrm{~mL}$. $\mathrm{kg}^{-1}$ Hypnorm and $2 \mathrm{mg} \cdot \mathrm{kg}^{-1}$ diazepam) was given before oral intubation with a cuffed tube of $3.0 \mathrm{~mm}$ diameter (Sheridan, Argyle, NY, USA). The anaesthesia was continued with i.v. infusion of $0.1-0.3 \mathrm{~mL} \cdot \mathrm{kg}^{-1} \cdot \mathrm{h}^{-1}$ Hypnorm, 
and with $2.5 \mathrm{mg}$ diazepam i.v. and $0.2 \mathrm{mg}$ pancuronium bromide $i . v$. when necessary.

The marginal ear vein was used for $i$.v. injections, while the ear artery was used for blood sampling and pressure monitoring. The rabbit was placed in the prone position on a heating pad to maintain normal body temperature. Artificial ventilation was given with a Siemens 900C ventilator (Siemens-Elema, Solna, Sweden) with an inspiratory oxygen fraction $\left(F \mathrm{I}, \mathrm{O}_{2}\right)$ of 0.3 , an inspiratory:expiratory (I:E) ratio of $1: 2$, a tidal volume of $38 \mathrm{~mL}$ and a ventilatory frequency of approximately $30 \mathrm{breaths} \cdot \mathrm{min}^{-1}$. The ventilatory frequency was adjusted to keep the end-tidal $\mathrm{CO}_{2}$ tension $\left(P\right.$ ET, $\left.\mathrm{CO}_{2}\right)$, measured with an Eliza duo (Datex-Engström, Bromma, Sweden), at around $5 \mathrm{kPa}$. After induction of anaesthesia, $30 \mathrm{~min}$ were allowed before the onset of the experiment. At the end of the experiment, muscle paralysis was antagonized with $0.15 \mathrm{mg}$ neostigmine and $0.03 \mathrm{mg}$ glycopyrron. In addition, i.v. naloxone was given to counteract hypoventilation due to the residual effects of Hypnorm.

\section{Measurements}

Arterial blood was drawn for the determination of arterial oxygen tension $\left(\mathrm{Pa}_{\mathrm{a}} \mathrm{O}_{2}\right)$ (ABL 300; Radiometer, Copenhagen, Denmark). The ratio of the $\mathrm{Pa}_{\mathrm{a}} \mathrm{O}_{2}$ to the $F \mathrm{I}, \mathrm{O}_{2}$ was used as an index of arterial oxygenation. NO (AGA AB, Lidingö, Sweden) was administered, as a gas mixture with $30 \%$ oxygen in nitrogen, to the low-pressure gas supply inlet of the ventilator. A soda lime canister was fitted into the breathing circuit to eliminate any nitrogen dioxide formed. The NO concentration was monitored in the inhalation gas using a chemiluminescence technique (Model 9841; Monitor Labs, Englewood, CO, USA).

The methaemoglobin (MetHb) concentration was determined by spectrophotometry (OSM 3; Radiometer) before and after NO inhalation. Mean arterial pressure (MAP) was continuously followed (Tram 7010; Marquette Electronics, Milwaukee, WI, USA). Respiratory resistance (Rrs) and lung compliance $(C \mathrm{rs})$ were obtained using the technique of inspiratory-hold manoeuvre after constant-flow inflation [13]. Pressure and flow signals were measured at the inspiratory side of the ventilator and fed into a computer for on-line signal processing by LabView 3.0 software (National Instruments, Austin, TX, USA). Volume and flow values were corrected for gas compression in the breathing circuit. $R$ rs is the difference between the maximum airway pressure and the pressure after a two-second endinspiratory pause, divided by the flow. $R \mathrm{rs}$ is presented with the endotracheal resistance of $28 \mathrm{cmH}_{2} \mathrm{O} \cdot \mathrm{L}^{-1} \cdot \mathrm{s}$ subtracted. $C_{\mathrm{rs}}$ was calculated as the tidal volume divided by the end-inspiratory pressure minus the end-expiratory pressure.

\section{Protocols}

Each protocol was divided into one experiment with NO and one experiment without NO inhalation in the same rabbits. The sequence of the experiments was randomized. There was a resting period of $\breve{S} 2$ weeks between experiments within a protocol. Rabbits participating in more than one protocol rested for $\breve{S} 2$ months between protocols.
Protocol 1: effects of nitric oxide inhalation on bronchoconstriction. This protocol served as a control to test whether NO had an effect on induced bronchoconstriction in the absence of airway wall oedema, as in earlier studies $[5,6]$. Eight rabbits were studied. NO was inhaled at a concentration of $80 \mathrm{ppm}$ for $10 \mathrm{~min}$ before and also during the meth challenge. Meth was nebulized at a concentration of $3 \mathrm{mg} \cdot \mathrm{mL}^{-1}$.

Protocol 2: effects of nitric oxide inhalation on bronchoconstriction after nebulization of hypertonic saline. Nebulization of phosphate-buffered hypertonic (3.6\%) saline, $\mathrm{pH}$ 7.0, was performed for $10 \mathrm{~min}$ (UltraNeb 99; DeVilbiss, Somerset, PA, USA). In preliminary experiments, the effects of this nebulization were shown to last for $>10 \mathrm{~min}$ but $<20 \mathrm{~min}$. This guided us to deliver NO at a concentration of $80 \mathrm{ppm}$ for $10 \mathrm{~min}$, after the nebulization of hypertonic saline. During NO inhalation, $3 \mathrm{mg} \cdot \mathrm{mL}^{-1}$ meth was nebulized in one experiment $(\mathrm{n}=7)$ and $1 \mathrm{mg} \cdot \mathrm{mL}^{-1}$ meth was nebulized in another experiment $(n=6)$. In a third experiment, the NO concentration was increased to $300 \mathrm{ppm}$, with nebulization of $1 \mathrm{mg} \cdot \mathrm{mL}^{-1}$ of meth $(\mathrm{n}=6)$. In the control experiments without NO, but with the same rabbits, there was a resting period of $10 \mathrm{~min}$ instead of NO inhalation before meth challenge. The meth was dissolved in sterile water and adjusted to a $\mathrm{pH}$ of $7.2 \pm 0.1$.

Protocol 3: effects of nitric oxide inhalation on bronchoconstriction after hyperventilation with dry gas. The rabbits $(n=7)$ were hyperventilated for 10 min with dry gas containing $\mathrm{NO}\left(30 \% \mathrm{O}_{2}, 5 \% \mathrm{CO}_{2}, 80 \mathrm{ppm} \mathrm{NO}\right.$ in $\left.\mathrm{N}_{2}\right)$. The response of the airway wall to dry air is rapid and transient over a period of $10 \mathrm{~min}$ [10]. The NO was therefore given during the hyperventilation. The ventilatory frequency was adjusted in order to increase minute ventilation to four times the resting condition. Ventilation was returned to the resting condition and bronchoconstriction was induced with meth at a concentration of $1 \mathrm{mg} \cdot \mathrm{mL}^{-1}$ during NO inhalation. The rabbits served as their own controls and were challenged on another occasion with hyperventilation and meth without NO inhalation.

\section{Statistical analysis}

Statistical analysis was carried out using SigmaStat software (Jandel Scientific, Erkrath, Germany). Student's two-tailed test was used for paired data and differences within the groups were tested with one-way analysis of variance (ANOVA) for repeated measurements and Student-Newman-Keul's test. Results are presented as mean values \pm SEM. A value of $\mathrm{p}<0.05$ was considered statistically significant.

\section{Results}

Baseline data of body weight and temperature as well as cardiac frequency $(f \mathrm{C}), \mathrm{MAP}, \mathrm{Pa}_{\mathrm{a}} \mathrm{O}_{2} / F \mathrm{I}, \mathrm{O}_{2}, P$ ET, $\mathrm{CO}_{2}, R_{\mathrm{rs}}$ and $C$ rs showed no significant differences between the experiments within or between protocols. To demonstrate the stability of this rabbit model, the baseline data from the first and second experiments, for all rabbits, are given in table 1. 
Table 1. - Baseline data from two experiments at least 2 weeks apart for the rabbits participating in different protocols

\begin{tabular}{lcc}
\hline & First experiment & Second experiment \\
\hline Body weight kg & $3.3 \pm 0.1$ & $3.3 \pm 0.1$ \\
Temperature ${ }^{\circ} \mathrm{C}$ & $38.1 \pm 0.2$ & $38.0 \pm 0.1$ \\
$f \mathrm{C}$ beats $\cdot \mathrm{min}^{-1}$ & $221 \pm 5$ & $220 \pm 7$ \\
$\mathrm{MAP} \mathrm{mmHg}$ & $70 \pm 2$ & $69 \pm 2$ \\
$P \mathrm{a}, \mathrm{O}_{2} / \mathrm{FI}_{\mathrm{I}} \mathrm{O}_{2} \mathrm{mmHg}$ & $79 \pm 1$ & $80 \pm 2$ \\
$P \mathrm{ET}, \mathrm{CO}_{2} \mathrm{kPa}$ & $5.4 \pm 0.1$ & $5.3 \pm 0.1$ \\
$R \mathrm{rs} \mathrm{cmH}_{2} \mathrm{O} \cdot \mathrm{L}^{-1} \cdot \mathrm{s}$ & $50 \pm 2$ & $52 \pm 2$ \\
$C \mathrm{rs} \mathrm{mL}^{\circ} \cdot \mathrm{cmH}_{2} \mathrm{O}^{-1}$ & $4.3 \pm 0.1$ & $4.5 \pm 0.1$ \\
\hline
\end{tabular}

Data are mean \pm SEM $(\mathrm{n}=16) . f \mathrm{C}$ : cardiac frequency; MAP: mean arterial pressure; $\mathrm{Pa}_{\mathrm{a}} \mathrm{O}_{2}$ : arterial oxygen tension; $\mathrm{FI}_{\mathrm{I}} \mathrm{O}_{2}$ : inspiratory oxygen fraction; $P \mathrm{ET}, \mathrm{CO}_{2}$ : end-tidal carbon dioxide tension; $R$ rs: respiratory resistance; $C_{\mathrm{rs}}$ : lung compliance. $(1 \mathrm{mmHg}=$ $0.133 \mathrm{kPa}$.)

\section{Protocol 1}

$\mathrm{NO}$ at a concentration of $80 \mathrm{ppm}$ reduced the bronchoconstriction in response to $3 \mathrm{mg} \cdot \mathrm{mL}^{-1}$ of meth $(\mathrm{p}<0.05)$ (fig. 1a). There was no significant difference in the decrease in $C$ rs due to meth with and without NO $(3.5 \pm 0.3 \mathrm{~mL}$. $\mathrm{cmH}_{2} \mathrm{O}^{-1}$ with $\mathrm{NO}$ and $3.4 \pm 0.4$ without NO). $\mathrm{Pa}, \mathrm{O}_{2} / F \mathrm{I}, \mathrm{O}_{2}$ decreased $(\mathrm{p}<0.05)$ by meth but there was no difference between the results with $(68 \pm 4 \mathrm{kPa})$ and without $\mathrm{NO}$ $(76 \pm 4 \mathrm{kPa})$. The MetHb concentration increased during NO inhalation, from $0.4 \pm 0.1$ to $0.8 \pm 0.1 \%(\mathrm{p}<0.01)$.

\section{Protocol 2}

The hypertonic saline nebulization per se did not affect the $\operatorname{Rrs}\left(52 \pm 1\right.$ before and $52 \pm 2 \mathrm{cmH}_{2} \mathrm{O} \cdot \mathrm{L}^{-1} \cdot \mathrm{s}$ after the hypertonic saline) in the rabbits studied. Meth, at a concentration of $3 \mathrm{mg} \cdot \mathrm{mL}^{-1}$, caused an increase in $R \mathrm{rs}$ of $86 \pm 15$ $\mathrm{cmH}_{2} \mathrm{O} \cdot \mathrm{L}^{-1} \cdot \mathrm{s}$ after hypertonic saline nebulization $(\mathrm{p}<0.001)$. $\mathrm{NO}$ inhalation at a concentration of $80 \mathrm{ppm}$ did not counteract the increase in $\operatorname{Rrs}\left(92 \pm 14 \mathrm{cmH}_{2} \mathrm{O} \cdot \mathrm{L}^{-1} \cdot \mathrm{s}\right)$ (fig. 1b).
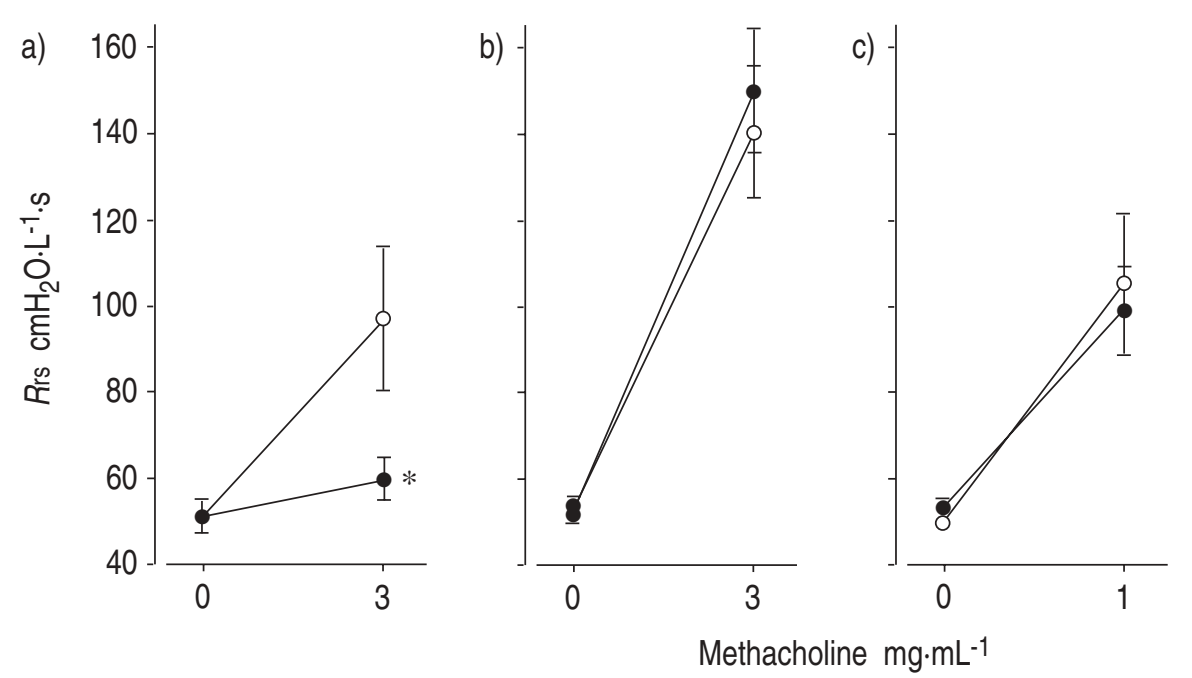

The Rrs response to meth after nebulization of hypertonic saline was stronger than without hypertonic saline. The $R \mathrm{rs}$ increase of $56 \pm 16 \mathrm{cmH}_{2} \mathrm{O} \cdot \mathrm{L}^{-1} \cdot \mathrm{s}$ from baseline $(\mathrm{p}<0.05)$, following $1 \mathrm{mg} \cdot \mathrm{mL}^{-1}$ meth, was not significantly altered by inhalation of $80 \mathrm{ppm} \mathrm{NO}\left(42 \pm 11 \mathrm{cmH}_{2} \mathrm{O} \cdot \mathrm{L}^{-1} \cdot \mathrm{s}\right)$ (fig. 1c). Not even inhalation with $\mathrm{NO}$ at a concentration of $300 \mathrm{ppm}$ altered the increase in Rrs from baseline in response to meth at a concentration of $1 \mathrm{mg} \cdot \mathrm{mL}^{-1}$. The increase in $R$ rs was $48 \pm 8 \mathrm{cmH}_{2} \mathrm{O} \cdot \mathrm{L}^{-1} \cdot \mathrm{s}(\mathrm{p}<0.05)$ with $\mathrm{NO}$ and $44 \pm 14 \mathrm{cmH}_{2} \mathrm{O}^{-\mathrm{L}^{-1} \cdot \mathrm{s}}(\mathrm{p}<0.05)$ without $\mathrm{NO}$ inhalation (fig. 1d).

$C_{\text {rs }}$ was significantly decreased after the hypertonic saline nebulization, from $4.5 \pm 0.1$ to $3.7 \pm 0.1 \mathrm{~mL} \cdot \mathrm{cmH}_{2} \mathrm{O}^{-1}$ $(\mathrm{p}<0.001)$. Meth provocation significantly decreased $C \mathrm{rs}$ at both 1 and $3 \mathrm{mg} \cdot \mathrm{mL}^{-1}$ meth. Inhalation of 80 or $300 \mathrm{ppm}$ NO did not significantly alter the reduction in $C_{\text {rs }}$ (table 2). $P \mathrm{a}, \mathrm{O}_{2} / F \mathrm{I}, \mathrm{O}_{2}$ was not affected by hypertonic saline or $\mathrm{NO}$ inhalation but was decreased by meth provocation $(\mathrm{p}<0.001)$ (table 2). There was a significant increase in MetHb concentration during NO inhalation $(\mathrm{p}<0.001)$ (table 2). The MAP, shown in table 1, was not altered by nebulization of hypertonic saline, meth or any concentration of NO.

\section{Protocol 3}

There was a significant increase in $R$ rs due to meth 1 $\mathrm{mg} \cdot \mathrm{mL}^{-1}(\mathrm{p}<0.05)$. The increase in resistance was $27 \pm 11$ $\mathrm{cmH}_{2} \mathrm{O} \cdot \mathrm{L}^{-1} \cdot \mathrm{s}^{-1}$ with $80 \mathrm{ppm} \mathrm{NO}$ and $28 \pm 5 \mathrm{cmH}_{2} \mathrm{O} \cdot \mathrm{L}^{-1} \cdot \mathrm{s}$ without NO (table 3). Meth at a concentration of $1 \mathrm{mg}$. $\mathrm{mL}$ caused a decrease in $C_{\mathrm{rs}}(\mathrm{p}<0.05)$, which was not observed during $\mathrm{NO}$ inhalation (table 3 ). $\mathrm{Pa}, \mathrm{O}_{2} / \mathrm{FI}_{\mathrm{I}} \mathrm{O}_{2}$ was increased by hyperventilation with and without $\mathrm{NO}$ inhalation, both to $82 \pm 2 \mathrm{kPa}$. The meth nebulization decreased the $\mathrm{Pa}, \mathrm{O}_{2} / F \mathrm{I}, \mathrm{O}_{2}$ ratio more with $\mathrm{NO}$ than without $\mathrm{NO}(\mathrm{p}<$ 0.05 ) (table 3 ). The MetHb concentration increased during 10 min of hyperventilation with 80 ppm NO $(\mathrm{p}<0.001)$ (table 3).

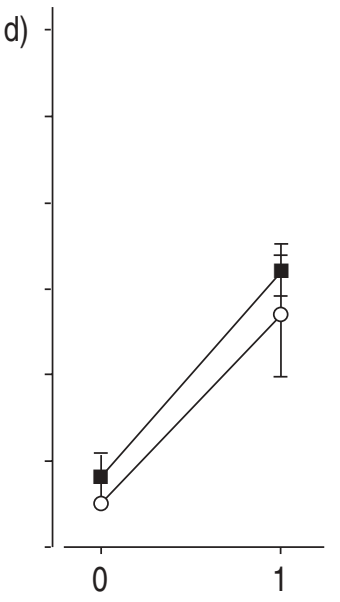

Fig. 1. - Respiratory resistance (Rrs) before and after nebulized methacholine (meth) without (O) and with nitric oxide inhalation at concentrations of $80(\bullet)$ and $300(\square)$ parts per million $(\mathrm{ppm})$. a) Changes in $R \mathrm{rs}$ induced by $3 \mathrm{mg} \cdot \mathrm{mL}^{-1}$ meth. NO inhalation countered the increase in $R \mathrm{rs}(*: \mathrm{p}<0.05)$. b) After nebulization of hypertonic (3.6\% saline) there was an increased response to meth which 80 ppm NO did not alter. c) Changes in $R$ rs induced by a lower concentration, $1 \mathrm{mg} \cdot \mathrm{mL}^{-1}$, of meth after nebulization of hypertonic saline. The increase in $R \mathrm{rs}$ was the same with and without $80 \mathrm{ppm}$ NO. d) A similar result was obtained with 300 ppm NO. 
Table 2. - Effect of nitric oxide (NO) inhalation after nebulization of hypertonic (3.6\%) saline on methacholine (meth)induced bronchoconstriction

\begin{tabular}{lccccc}
\hline & $3 \mathrm{mg} \cdot \mathrm{mL}^{-1}$ Meth & $\begin{array}{c}3 \mathrm{mg} \cdot \mathrm{mL}^{-1} \text { Meth } \\
\text { plus } 80 \mathrm{ppm} \mathrm{NO}\end{array}$ & $1 \mathrm{mg} \cdot \mathrm{mL}^{-1}$ Meth & $\begin{array}{c}1 \mathrm{mg} \cdot \mathrm{mL}^{-1} \mathrm{Meth} \\
\text { plus } 80 \mathrm{ppm} \mathrm{NO}\end{array}$ & $\begin{array}{c}1 \mathrm{mg} \cdot \mathrm{mL}^{-1} \\
\text { plus } 300 \mathrm{ppm} \mathrm{NO}\end{array}$ \\
\hline $\mathrm{n}$ & 7 & 7 & 6 & 6 & 6 \\
$R \mathrm{rs} \mathrm{cmH}_{2} \mathrm{O} \cdot \mathrm{L}^{-1} \cdot \mathrm{s}$ & $140 \pm 15$ & $150 \pm 14$ & $105 \pm 16$ & $96 \pm 0.10$ & $104 \pm 6$ \\
$\mathrm{Crs} \mathrm{mL}_{\mathrm{ramH}} \mathrm{C}^{-1}$ & $1.8 \pm 0.1$ & $1.7 \pm 0.1$ & $3.0 \pm 0.2$ & $2.8 \pm 0.3$ & $3.4 \pm 0.2$ \\
${\mathrm{~Pa}, \mathrm{O}_{2} / F \mathrm{I}, \mathrm{O}_{2} \mathrm{kPa}}_{\mathrm{MetHb} \%}$ & $35 \pm 4$ & $35 \pm 2$ & $56 \pm 5$ & $50 \pm 5$ & $60 \pm 9$ \\
$\mathrm{P}$ & $0.6 \pm 0.1$ & $0.9 \pm 0.1^{*}$ & $0.6 \pm 0.2$ & $1.0 \pm 0.1^{*}$ & $1.9 \pm 0.2^{*}$ \\
\hline
\end{tabular}

Data are means ( \pm SEM). For baseline measurements see table 1. Rrs: respiratory resistance; $C_{\mathrm{rs}}$ : lung compliance; $P \mathrm{a}, \mathrm{O}_{2}:$ arterial oxygen tension; $\mathrm{F}_{\mathrm{I}} \mathrm{O}_{2}$ : inspiratory oxygen fraction; MetHb: methaemoglobin; ppm: parts per million. *: $\mathrm{p}<0.05$, significantly different from control situation without $\mathrm{NO}$ inhalation.

\section{Discussion}

The major finding in this study is that the inhibitory effect of NO inhalation on induced bronchoconstriction can be blocked, either by nebulization of hypertonic saline or by hyperventilation with dry gas. This could possibly be due to the formation of oedema, acting as a diffusion barrier or as a metabolic sink, or by the hyperosmolar airway perse.

One possible explanation for the inhibition of the NO effect is that the oedematous airway wall acts as a diffusion barrier for NO. Nebulization of hypertonic saline is known to increase production of mucus. Mucus on the surface of the epithelial layer may also contribute to a diffusion barrier. However, NO is extremely lipophilic [14] and its diffusing capacity in the lung is four times that of carbon monoxide [15]. It therefore seems unlikely that the transport of NO to the airway smooth muscle should have been totally blocked. Support for this argument is the significant increase in MetHb seen in the present study. If the increase in MetHb due to $300 \mathrm{ppm}$ NO inhalation is compared to a previous study [6], the increases are identical with and without hypertonic saline nebulization, i.e. $112 \pm 4$ and $112 \pm 12 \%$, respectively. Hence, the lung vasculature and, therefore, probably also the bronchial airway wall were exposed to NO.

The mucus can act not only as a physical barrier but also as a metabolic sink for NO. Oxygen free radicals $\left(\mathrm{O}_{2}^{-}\right)$are known to be present in the mucus [16]. NO will rapidly form the peroxynitrate anion $\left(\mathrm{OONO}^{-}\right)$in contact with $\mathrm{O}_{2}^{-}$. The $\mathrm{O}_{2}^{-}$-rich environment of the lung, together with the low $\mathrm{pH}$ of the airway lining fluid, favour OONOformation in the respiratory system [17].

Recent observations suggest that inhaled $\mathrm{NO}$ also reacts with thiol constituents in the surface liquid layer of the

Table 3. - Effect of hyperventilation with dry gas and nitric oxide (NO) inhalation on methacholine (meth)-induced bronchoconstriction

\begin{tabular}{lcc}
\hline & $1 \mathrm{mg} \cdot \mathrm{mL}^{-1}$ Meth & $\begin{array}{c}1 \mathrm{mg} \cdot \mathrm{mL}^{-1} \text { Meth } \\
\text { plus } 80 \mathrm{ppm} \mathrm{NO}\end{array}$ \\
\hline $\mathrm{n}$ & 7 & 7 \\
$R \mathrm{rs} \mathrm{cmH} \mathrm{C}_{2} \cdot \mathrm{L}^{-1} \cdot \mathrm{s}$ & $74 \pm 6$ & $81 \pm 10$ \\
$C \mathrm{rs} \mathrm{mL} \cdot \mathrm{cmH}_{2} \mathrm{O}^{-1}$ & $3.0 \pm 0.3$ & $3.6 \pm 0.3$ \\
$P \mathrm{a}, \mathrm{O}_{2} / F \mathrm{I}, \mathrm{O}_{2} \mathrm{kPa}$ & $66 \pm 4$ & $59 \pm 5^{*}$ \\
$\mathrm{MetHb} \%$ & $0.5 \pm 0.1$ & $1.5 \pm 0.1^{*}$ \\
\hline
\end{tabular}

Data are means ( \pm SEM). For baseline measurements see table 1 . $R$ rs: respiratory resistance; $C_{\mathrm{rs}}$ : lung compliance; $\mathrm{P}_{\mathrm{a}, \mathrm{O}_{2}}$ : arterial oxygen tension; $\mathrm{F}_{\mathrm{I}} \mathrm{O}_{2}$ : inspiratory oxygen fraction; MetHb: methaemoglobin; ppm: parts per million. ${ }^{*}: \mathrm{p}<0.05$, significantly different from the control situation without NO. airway wall, forming stable bioactive S-nitrosothiols [17]. Therefore, reactions between NO and other cellular and chemical constituents of the airway are likely. Deactivation of the NO molecule could explain the lack of effect on airway smooth muscle found in this study.

Another possible explanation for the lack of effect of the inhaled NO could be the hyperosmolarity induced by hypertonic saline nebulization or by hyperventilation. One hypothesis is that the hyperosmolarity per se may inactivate the NO molecule. Further support for this comes from previous rabbit studies, where inhalation of $\mathrm{NO}$ at a concentration of $300 \mathrm{ppm}$ decreased the MAP and the lung compliance $[6,18]$. In this study, after hypertonic saline nebulization, these effects were abolished.

The increase in reactivity to meth after nebulization of hypertonic saline and hyperventilation can only be speculated. Normally, endogenous NO is involved in the inhibition bronchoconstriction. If the production of $\mathrm{NO}$ is blocked by NO synthase inhibitors, one could expect a hyperreactive response to the bronchial challenge. Indeed, NIJKAMP et al. [19] demonstrated that the in vitro luminal perfusion of guinea-pig tracheal tubes with NO synthesis inhibitors increased the maximum on the histamine concentration-response curve by $335 \%$. This effect could also be achieved by removal of the airway epithelium, which is a production site for NO. Production or NO or a NOlike factor has been shown to be impaired in the rat tail artery by superfusion with hyperosmolar fluid [20]. This superfusion also gave rise to an enhancement of phenylephrine-induced contraction. Therefore, the inhibition of endogenous NO as well as exogenous NO could be one reason for the increased reactivity to induced bronchoconstriction seen in the rabbits in the present study.

In conclusion, the relaxant effect of nitric oxide inhalation on airway smooth muscle can be blocked by altering the osmolarity of the airway surface. The mechanism of this inhibition remains to be established.

\section{References}

1. Tucker J, Brave S, Charalambous L, Hobbs A, Gibson A. L- $N \mathrm{~N}^{\mathrm{G}}-\mathrm{Nitro}$ arginine inhibits non-adrenergic, non-cholinergic relaxation of guinea pig isolated tracheal smooth muscle. Br J Pharmacol 1990; 100: 663-664.

2. Belvisi MG, Stretton CD, Barnes PJ. Nitric oxide is the endogenous neurotransmitter of bronchodilator nerves in human airways. Eur J Pharmacol 1992; 210: 221-222.

3. Lammers JWJ, Barnes PJ, Chung KF. Non-adrenergic, non-cholinergic airway inhibitory nerves. Eur Respir $J$ 1992; 5: 239-246.

4. Dupuy PM, Shore SA, Drazen JM, Frostell C, Hill WA, 
Zapol WM. Bronchodilator action of inhaled nitric oxide in guinea pigs. $J$ Clin Invest 1992; 90: 421-428.

5. Högman M, Frostell CG, Arnberg H, Hedenstierna G. Inhalation of nitric oxide modulates methacholine-induced bronchoconstriction in the rabbit. Eur Respir J 1993; 6: 177-180.

6. Högman M, Wei SZ, Frostell C, Arnberg H, Hedenstierna G. Effects of inhaled nitric oxide on methacholine-induced bronchoconstriction: a concentration response study in rabbits. Eur Respir J 1994; 7: 698-702.

7. Brown RH, Zerhouni EA, Hirshman CA. Reversal of bronchoconstriction by inhaled nitric oxide. Histamine versus methacholine. Am J Respir Crit Care Med 1994; 150: 233-237.

8. Högman M, Frostell CG, Hedenström H, Hedenstierna G. Inhalation of nitric oxide modulates adult human bronchial tone. Am Rev Respir Dis 1993; 148: 1474-1478.

9. Sanna A, Kurtansky A, Veriter C, Stanescu D. Bronchodilator effect of inhaled nitric oxide in healthy men. Am J Respir Crit Care Med 1994; 150: 1702-1704.

10. Anderson SD. Is there a unifying hypothesis for exerciseinduced asthma? J Allergy Clin Immunol 1984; 73: 660665.

11. Högman M, Hjoberg J, Mörk A, Roomans GM, Anderson SD. Dry gas hyperpnea changes airway reactivity and ion content of rabbit tracheal wall. Respir Physiol 1997; 109: 65-72.

12. Högman M, Almirall J, Mörk A, et al. Nebulisation of hypertonic saline causes oedema of the airway wall. $J$ Submicr Cytol Pathol 1997; 29: 59-64.
13. Bates JHT, Milic-Emili J. The flow interruption technique for measuring respiratory resistance. J Crit Care 1991; 4: 227-238.

14. Shaw AW, Vosper AJ. Solubility of nitric oxide in aqueous and nonaqueous solvents. $J$ Chem Soc Faraday Trans 1 1977; 73: 1239-1244.

15. Cremona G, Higenbottam T, Borland C, Mist B. Mixed expired nitric oxide in primary pulmonary hypertension in relation to lung diffusion capacity. $Q J$ Med 1994; 87 : 547-551.

16. Cross CE, Halliwell B, Allen A. Antioxidant protection: a function of tracheobronchial and gastrointestinal mucus. Lancet 1984; 1: 1328-1330.

17. Gaston B, Drazen JM, Loscalzo J, Stamler JS. The biology of nitrogen oxides in the airways. Am J Respir Crit Care Med 1994; 149: 538-551.

18. Högman M, Frostell C, Arnberg H, Sandhagen B, Hedenstierna G. Prolonged bleeding time during nitric oxide inhalation in the rabbit. Acta Physiol Scand 1994; 151: 125-129.

19. Nijkamp FP, Vanderlinde HJ, Folkerts G. Nitric oxide synthesis inhibitors induce airway hyperresponsiveness in the guinea pig in vivo and in vitro - role of the epithelium. Am Rev Respir Dis 1993; 148: 727-734.

20. Rocha G, Bucher B, Tschopl M, Stoclet JC. Hyperosmolarity enhances smooth muscle contractile responses to phenylephrine and partially impairs nitric oxide production in the rat tail artery. $J$ Vasc Res 1995; 32: 5865 . 